refusers confirmed earlier findings that problems with social relationships persist and that psychiatric referrals are common when they are adults. ${ }^{25}$

Such studies, however, predate the current use of family therapy, and research is now called for on the effectiveness of this treatment. School refusal therefore remains a challenge, perhaps comparable to an unexplained fever. Though it may resolve spontaneously, it may have serious implications justifying prompt referral and a full investigation with the participation of not only the whole family but also the school and educational authorities.

JIM WATTERS

Senior Registrar,

Child and Family Department,

Tavistock Clinic, London NW3

1 Fogelman K, Richardson K. School attendance: some findings from the National Child Development Study. In: Turner B, ed. Truancy. London: Lock, 1974:29-51.

Prentice R. Parliamentary written answer. House of Commons Official Report (Hansard) 1974;877 $532-40$

3 Hersov LA. Persistent non-attendance at school. $\mathcal{F}$ Child Psychol Psychiatry 1960;1:130-6.

+ Broadwin IT. A contribution to the study of truancy. Am f Orthopsychiatry 1932;2:253-9.

5 Johnson AM, Falstein EI, Szurek SA, Svendsen M. School phobia. Am f Orthopsychiatr 1941:11:702-11.

6 Yates AJ. Behavior therapy. New York: Wiley, 1970 .
7 Eisenberg L. School phobia: a study of the communication of anxiety. Am $\mathcal{f}$ Psychiatry 1958:114:712-8.
8 Hersov L. School refusal In: Rutter M, Hersov L, eds. Child and adolescent psychiatry: modern approaches. London: Blackwell, 1985:382-99.

9 Moore T. Difficulties of the ordinary child in adjusting to primary school. 7 Child Psychol Psychiatry 1966;7:17-38.

0 Shepherd M, Cooper B, Brown AC, Kalton G. Psychiatric illness in general practice. Oxford: Oxford University Press, 1981:60-8.

1 Schmitt BD. School phobia-the great imitator: a paediatrician's viewpoint. Paediatrics 1971;48 433-41.

2 Barker $P$. The in-patient treatment of school refusal. Brf Med Psychol 1968;41:381-7.

13 Kolvin I, Berney TP, Bhate SR. Classification and diagnosis of depression in school phobia. Brf Psychiatry 1984;145:347-57

4 Shaffer D. Suicide in children and early adolescence. $\mathcal{F}$ Child Psychol Psychiatry 1974;15:275-91.

15 Bernstein GA, Garfinkel BD. School phobia: the overlap of affective and anxiety disorders. Fournal of the American Academy of Child Psychiatry 1986;25:235-41.

6 Davidson S. School phobia as a manifestation of family disturbance: its structure and treatment. f Child Psychol Psychiatry 1960;1:270-87.

17 Waldfogel S, Coolidge JC, Hahn PB. Development, meaning and management of school phobia. Am J Orthopsychiatry 1957;27:754-80.

8 Malmquist CP. School phobia. A problem in family neurosis. foumal of the American Academy of Child Psychiatry 1965;4:293-319.

19 Sperling M. School phobia: classification, dynamics and treatment. Psychoanal Study Child 1967;22:375-401.

20 Blagg NR, Yule W. The behavioural treatment of school refusal: a comparative study. Behav Res Ther 1984;22:119-27

21 Mansdorf IJ, Lukens E. Cognitive-behavioural psychotherapy for separation anxious children exhibiting school phobia. Fournal of the American Academy of Child Psychiatry 1987;26:222-5.

22 Gurman AS, Kniskern DP. Handbook of family therapy. New York: Brunner/Mazel, 1981

23 Kennedy WA. A behaviouristic community orientated approach to school phobia and other disorders. In: Richard HC, ed. Behavioural intervention in human problems. Oxford: Pergamon, 1971:37-60.

24 Simeon JG, Ferguson HB. Recent developments in the use of antidepressant and anxiolytic medications. Psychiatr Clin North Am 1985;8:893-907.

25 Flakierska N, Lindstrom M, Gillberg C. School refusal: a 15-20 year follow-up study of 35 Swedish urban children. $\operatorname{Br} \mathcal{F}$ Psychiatry 1988:152:834-7.

\title{
The solitary pulmonary nodule
}

\section{Various management strategies but little to choose between them}

Patients are commonly referred to chest physicians because a solitary pulmonary nodule is found by chance in their chest radiograph. They usually have no symptoms, and the problem is to distinguish benign from malignant disease.

Before embarking on expensive and invasive investigations the doctor should confirm that the lesion is within the lung. The skin should be examined for any soft tissue mass, and if necessary its relation to the lesion in the radiograph should be investigated by taking repeat films and using a surface marker. A benign pleural plaque may be confused with a solitary pulmonary nodule but may be distinguished by tomography or fluoroscopy: a pleural mass does not move relative to the chest wall with respiration. A full physical examination should be performed on patients with a solitary pulmonary nodule because the nodule may be a metastasis from the breast, kidney, testis, or ovary.

Many attempts have been made to establish radiological criteria for evaluating the solitary pulmonary nodule. ${ }^{1}$ Benign nodules are apt to be smaller than malignant lesions. An irregular, lobulated, or spiculated contour is suggestive of malignancy, whereas a smooth contour suggests that the nodule is benign, but there are important exceptions. The two most useful radiological criteria for excluding malignancy are no growth over two years and the presence of calcium. No growth almost completely rules out malignancy, and hence a search for old radiographs may be rewarding. The diagnostic value of calcium depends on the radiological pattern: a dense central nidus or a laminated or diffuse pattern are reliable signs of healed granulomas, but malignancy may still develop in relation to the granulomas. Pepper pot calcification is associated with hamartomas. Calcification may sometimes be seen within a malignant lesion, ${ }^{2}$ and so a lesion cannot be diagnosed as benign simply because of calcification. Computed tomography has been proposed as a reliable way of diagnosing benign disease, but early successful studies ${ }^{3+}$ have not been confirmed.
A doctor has three possible options in managing a solitary pulmonary nodule: to do nothing, to undertake invasive investigations, or to perform a thoracotomy. As an operation offers the only chance of curing local malignant disease the initial approach is determined by the probability of malignancy and the possibility of surgery. Primary bronchial malignancy is rare in non-smokers and patients under 35, but the possibility of a solitary secondary tumour from a breast or testicular primary tumour or a lymphoma must not be ignored. Geographical and ethnic factors may point towards granulomatous or hydatid disease.

Controversy exists whether biopsy should be performed before a surgical operation. A negative result seldom excludes malignancy, and a positive result in a fit patient leads to a thoracotomy. Therefore if a lesion seems to be operable and the patient could tolerate a thoracotomy we perform computed tomography of the abdomen and thorax. If no distant or mediastinal metastases are found then a thoracotomy is recommended for a "cure" or definitive diagnosis. The patient should be made aware of the diagnostic aspect of the operation and apprised of the possibility of some of the lung being resected despite benign disease. Thus in the patient with operable disease the lesion must be assumed to be malignant unless it can be proved to be benign or the chances of malignancy are so low that a short period of careful observation can be justified.

In the patient for whom an operation is contraindicated by poor lung function, age, coexistent cardiovascular disease, or by the results of computed tomography further management is influenced by symptoms and the probability of malignant disease. ${ }^{5}$ In an older patient with no symptoms we watch and wait. In a younger patient or a patient with symptoms further management will be influenced by whether malignancy is positively diagnosed. Bronchoscopy is safe and well tolerated but depends on the chance of reaching a bronchus that will lead into the lesion. Biopsy or needle aspiration through the 


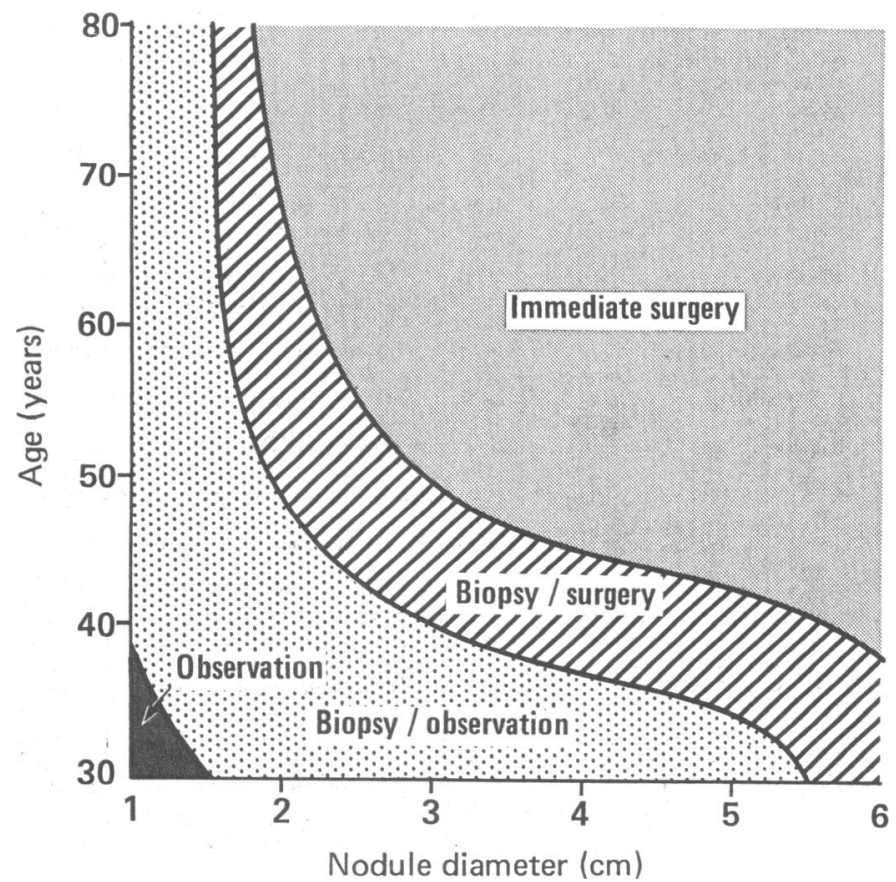

Management strategies for solitary pulmonary nodule that produced the longest average life expectancy in smokers according to age and diameter of nodule. In a 40 year old smoker with a $2 \mathrm{~cm}$ nodule, for example, biopsy and observation would produce the greatest life expectancy, whereas for a 60 year old with a $4 \mathrm{~cm}$ nodule it would be immediate surgery." "Reproduced with the permission of the "American Review of Respiratory Disease")

bronchoscope with fluoroscopy improves the chances of a positive diagnosis." A diagnosis may be made by transbronchial lung biopsy in a quarter of cases in which the nodules are smaller than $2 \mathrm{~cm}$ and in about two thirds of cases in which they are larger. Percutaneous needle biopsy is simpler but is contraindicated by a bleeding diathesis; severely compromised lung function; pulmonary hypertension; or suspicion of an hydatid cyst, arteriovenous malformation, or a sequestrated lung segment. In malignant lesions the diagnostic yield from needle biopsy increases with increasing size, reaching $80-90 \%$ for single samples from tumours larger than $3 \mathrm{~cm}$ and $95 \%$ for two or three samples.

An attempt has been made to evaluate the effect of these three management strategies (an operation, biopsy, or observation) on life expectancy by using decision analysis.? The figure shows the management strategies that produced the longest life expectancies for smokers at specific ages and with tumours of different diameters. The most interesting finding was that the differences between the strategies was surprisingly small. Other factors-such as the patient's own preference-may thus be given considerable weight in reaching the final decision on what to do.

DUNCAN M GEDDES Consultant Physician

MARK ELLIOTT

Brompton Hospital, Registrar in Thoracic Medicine

London SW3 6HP

\footnotetext{
1 Theros EG. Varying manifestations of peripheral pulmonary neeplasms: a radiologic, pathological correlative study. AfR 1977;128:893-914.

2 ()'Keefe ME, Good CA, McDonald JR. Calcification in solitary nodules of the lung. AfR 1957;77:1023-33.

3 Siegelman SS, Zerhouni EA, Leo RB, Khouri NF, Stitik FP. CT of the solitary pulmonary nodule. AfR 1980;135:1-13

4 Zerhouni EA, Stitik FP, Siegelman SS, et al. Computed tomography of the solitary pulmonary nodule. A national cooperative study. Radiologv 1986;160:319-27.

5 Cummings SR, Lillington GA, Richard RJ. Estimating the probability of malignancy in solitary pulmonary nodules. Am Rev Respir Dis 1986;134:449-52.

6 Wang KP, Haponik EF, Britt EJ, Khouri N. Transbronchial needle aspiration of peripheral pulmonary nodules. Chest 1984;86:819-23.

7 Cummings SR, Lillington GA, Richard RJ. Managing solitary pulmonary nodules. Am Rev Respir Dis 1986;134:453-60.
}

\section{Industrial accidents}

\section{Underreported and not improving}

The release of radiation at Chernobyl and methyl isocyanate at Bhopal drew international public attention to the severe consequences of accidents in the workplace. In Britain this attention has been heightened by the rail crash at Clapham Junction, the sinking of a ferry at Zeebrugge, and the fire and explosion on the Piper Alpha oil rig. Industrial accidents may kill, injure, and disable employees and members of the public. British data released just before Christmas estimated that there were 1.6 fatal injuries for every 100000 employees

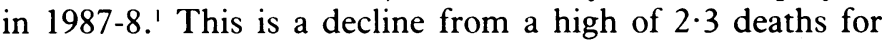
every 100000 employees in 1982 to 1.7 in 1986-7. This decline is probably explained, however, by the increase in people working in the less dangerous service sector: the yearly specific rate of fatal injuries was virtually unchanged from 1981 to $1987-8$.

In $1987-8$ the construction industry had more than five times the fatal injury rate of the manufacturing sector, which in turn experienced three times the rate of the service sector. In the five years from 1981 to 1985 there were 739 deaths in the construction industry; falls from roofs and scaffolds were a major cause. ${ }^{2}$ The deaths inclued 37 adult members of the public and 21 children. Data on sudden death at work for an industrial county in the United States also showed that men employed in the construction industry had the highest age adjusted rate of fatal injuries at work $(24 \cdot 3$ for every 100000 employees). ${ }^{3}$ For each year from 1981 to 1985, however, mining and quarrying in Britain had more deaths at work for every 100000 employees than construction, although the figures were distorted by the effects of the miners' strike from March 1984 to March $1985 .^{+}$

Figures on fatal accidents tend to be well documented, but data on major injuries not resulting in death tend to be underreported. Hashemi provided emergency care for injured forklift truck drivers and found that many of the accidents that caused time to be lost were not reported. ${ }^{5}$ Underreporting may occur because of changes in the requirements under which certain work injuries have to be notified.' A lack of awareness of new criteria-such as the need to notify all injuries resulting in three or more days off work - may lead to an initial shortfall in reporting. Also employers or employees may be reluctant to go through the process of notification, especially if the accident seems not to have resulted in obvious disability. Similarly, data on minor injuries and dangerous occurrences not resulting in injury are grossly underestimated. The less serious the injury and the shorter the sickness absence that results the less likely it is to be reported.

This underreporting of accidents inhibits study of what is an eminently preventable cause of premature death and 